\title{
Examination of the heart in supine and left lateral positions
}

\author{
H. J. N. Bethell ${ }^{1}$ and P. G. F. Nixon \\ From the Cardiac Department, Charing Cross Hospital, London
}

The purpose of this study was to assess the differences in the diastolic pulsations and sounds at the cardiac apex when examining the heart in the supine and left lateral positions. Fifty-eight patients with an atrial gallop and/or third heart sound were examined in the two positions by the techniques of apex cardiography and phonocardiography. In nearly all cases the amplitudes of the apical diastolic heart sounds and movements were much greater in the left lateral position, and, frequently, movements and sounds which could be recorded in the left lateral position were absent in the supine. It is suggested that, in view of the valuable information about left ventricular function which can be deduced from these signs, the palpation and auscultation of the heart with the patient lying on his left side should be a routine part of all examinations of the cardiovascular system.

The young and healthy heart fills and swells vigorously in early diastole. This rapid filling movement usually ends in a jerk which may be large enough to be visible and palpable through the chest wall at the cardiac apex, and often creates vibrations in the audible range, recognized as the physiological third heart sound. The ventricular filling movement continues more gradually through the rest of diastole and the presystolic left atrial contraction rarely produces a palpable or audible impulse. One of the earliest signs of disordered left ventricular function is a modification of its filling pattern. The early diastolic rapid filling movement becomes smaller and the physiological third sound disappears. As these changes proceed, the presystolic movement caused by left atrial contraction grows larger and may become palpable and audible as the atrial gallop (fourth heart sound, presystolic gallop). When left ventricular function is grossly disordered and frank heart failure is approaching, the presystolic movement wanes while the early diastolic movement waxes again and presents as the pathological third sound (protodiastolic gallop, ventricular gallop). At this stage the mean left atrial pressure is usually 20 $\mathrm{mmHg}$ or more (Taylor and Nixon, 1972).

The recognition of these changes in cardiac filling events provides a sensitive bedside method for the detection of early heart disease and the assessment

Received 12 March 1973.

${ }^{1}$ In receipt of a Research Fellowship from the Board of Governors, Charing Cross Hospital. of variations in left ventricular function, often before these are apparent from the electrocardiogram or chest $x$-ray. In clinical practice the appreciation of these signs appears to be greatly eased by examining the patient in the left lateral position, usually reserved for the detection of faint mitral murmurs.

The diastolic movements and sounds can be recorded by apex cardiography and phonocardiography. In this study we have compared the recorded findings in the supine and left lateral positions.

\section{Patients and methods}

Studies were made of 58 patients with a clinically detectable atrial gallop (a fourth sound and/or a palpable atrial contraction) and/or a third sound: $4 \mathrm{I}$ had atrial gallops, 6 had third sounds, and II had both. There were 5I men and 7 women, with an age range of 24 to $8 I$ (mean 55). The cardiac diagnosis was ischaemic and/or hypertensive heart disease in 56 and a normal heart in 2. There were no cases of valvar or congenital heart disease.

In each case, recordings of the apex cardiogram and the apical phonocardiogram were taken in the supine position and the left lateral position. In the supine position, the patient was propped up at an angle of $30^{\circ}$ to the horizontal and the recording was taken at the point of maximum impulse or, when no apex pulsation could be felt, from the point near the expected cardiac apex where the heart sounds were most clearly audible. In the left lateral position the angle of recline was adjusted to present the maximum area of left ventricle to the chest wall, and the recording was taken from the point of greatest impulse. 


\section{Apparatus}

The recording apparatus has been described in detail elsewhere (Nixon, Hepburn, and Ikram, I964). It consists of a displacement transducer which is a metal probe, sensitive to movements along its axis, mounted in a perspex cylinder and applied to the chest wall by hand (Fig. I). Side mounted into the cylinder is a crystal microphone which is used for picking up low frequency sounds. The recordings of apex movements and sounds, together with lead II of the electrocardiogram are fed into a Cambridge physiological recorder, displayed on an oscilloscope, and photographed for permanent records (Fig. 2).

The apex displacement transducer was set up to amplify diastolic events, a $0.2 \mathrm{~mm}$ movement of the probe producing a recording deflection of $5 \mathrm{~cm}$. The maximum probe displacement which could be recorded was approximately $0.4 \mathrm{~mm}$. This allowed the diastolic excursion to be written in full but cut off the peak of a large systolic movement.

Chest wall movements which produce probe displacements of more than $0.2 \mathrm{~mm}$ are usually readily palpable, while those producing movements of $0.08 \mathrm{~mm}$ or less are usually difficult or impossible to feel. Factors such as the frequency of a movement, its force, and its time relation to other movements affect its palpability, but displacement was selected as the aspect of motion most amenable to reproduction and study. Recorded movements have been divided into four groups: absent, small ( $0.08 \mathrm{~mm}$ or less, usually impalpable), moderate (0.09 $\mathrm{mm}$ to $0.20 \mathrm{~mm}$, often, but not always, palpable), and large (more than $0.20 \mathrm{~mm}$, nearly always easily palpable).

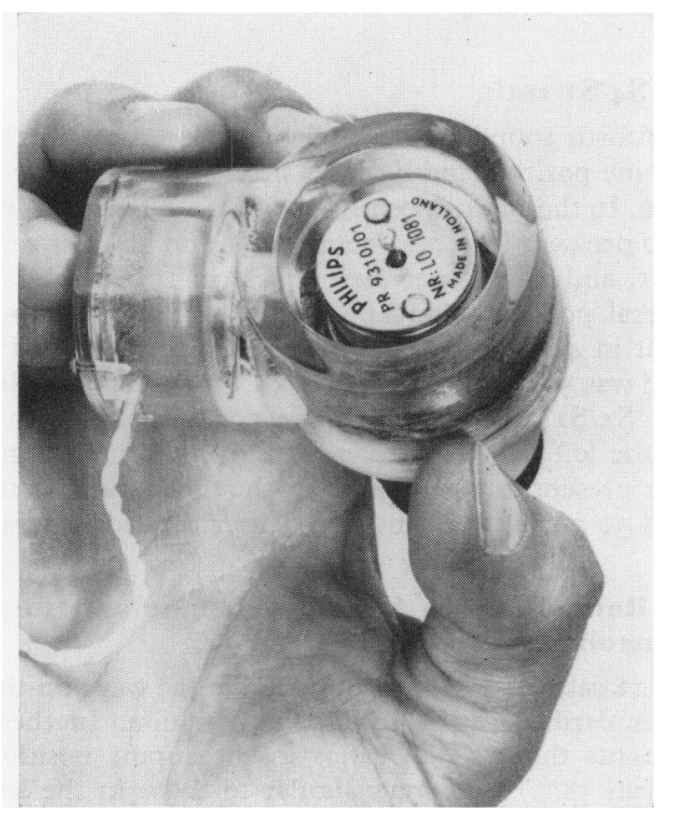

FIG. I Apex displacement transducer with sidemounted microphone.

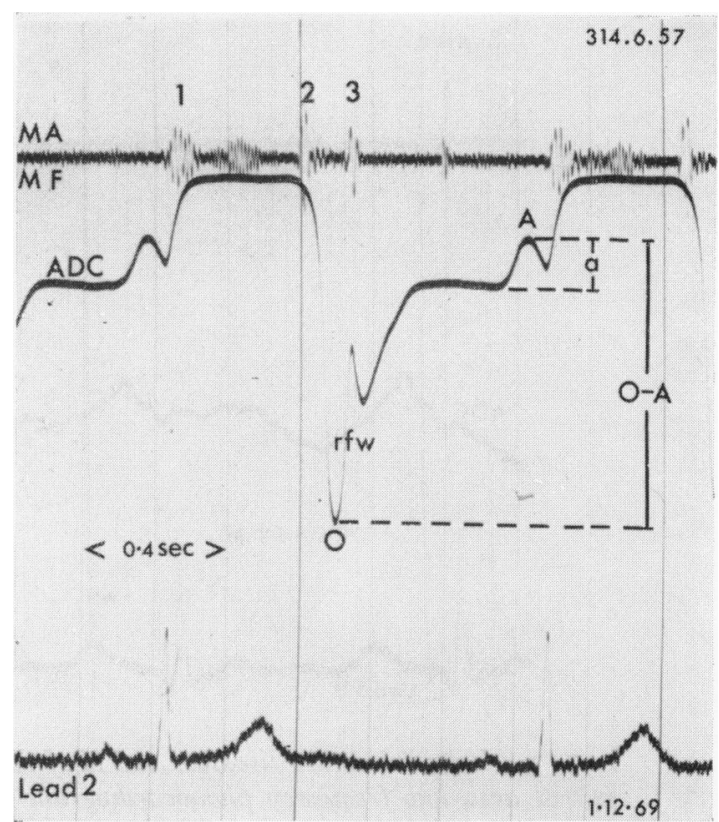

FIG. 2 Normal heart. Lead II of the electrocardiogram, apex cardiogram $(A D C)$ and mitral area medium frequency phonocardiogram $(M A M F)$. Note the large amplitude rapid filling wave ( $r f w)$ starting at the ' $O$ ' point, and ending with the third heart sound, and the small amplitude ' $a$ ' wave. The ratio $a / O-A$ is less than 40 per cent in normal subjects.

The low frequency phonocardiograph (Leatham, 1952) was modified by the use of a large air chamber. The amplitudes of the third and fourth heart sounds ( $S_{3}$ and $S_{4}$ ) have been expressed as percentages of the amplitudes of the succeeding first sounds $\left(\mathrm{SI}_{\mathrm{I}}\right.$ ), i.e. the $\mathrm{S}_{3} / \mathrm{S}_{\mathrm{I}}$ ratio and $\mathrm{S}_{4} / \mathrm{S}_{\mathrm{I}}$ ratio.

The following measurements in the two positions have been made in each case (Fig. 2). (I) Total apex displacement; (2) total ' $a$ ' wave height; (3) $\mathrm{S}_{3} / \mathrm{S}_{1}$ ratio; (4) $\mathrm{S}_{4} / \mathrm{S}_{\mathrm{I}}$ ratio; ( 5 ) the ratio between the ' $a$ ' wave height and the total diastolic excursion (' $\mathrm{a}$ ' $/ \mathrm{O}-\mathrm{A}$ ); and (6) the interval between the onset of the fourth sound and the onset of the first sound ( $\mathbf{S}_{4}-\mathrm{S}_{1}$ interval).

\section{Results}

\section{I) Total apex displacement}

In the supine position this was classified as large in 16, moderate in 9, small in 21 , and absent in 12 . In the left lateral position it was large in 52 and moderate in the remaining 6 . Thus the apex beat was in the easily palpable category in 28 per cent in the supine position and in the difficult or impossible to palpate category in 58 per cent. Turning the patient on his left side brought 90 per cent into the easily 


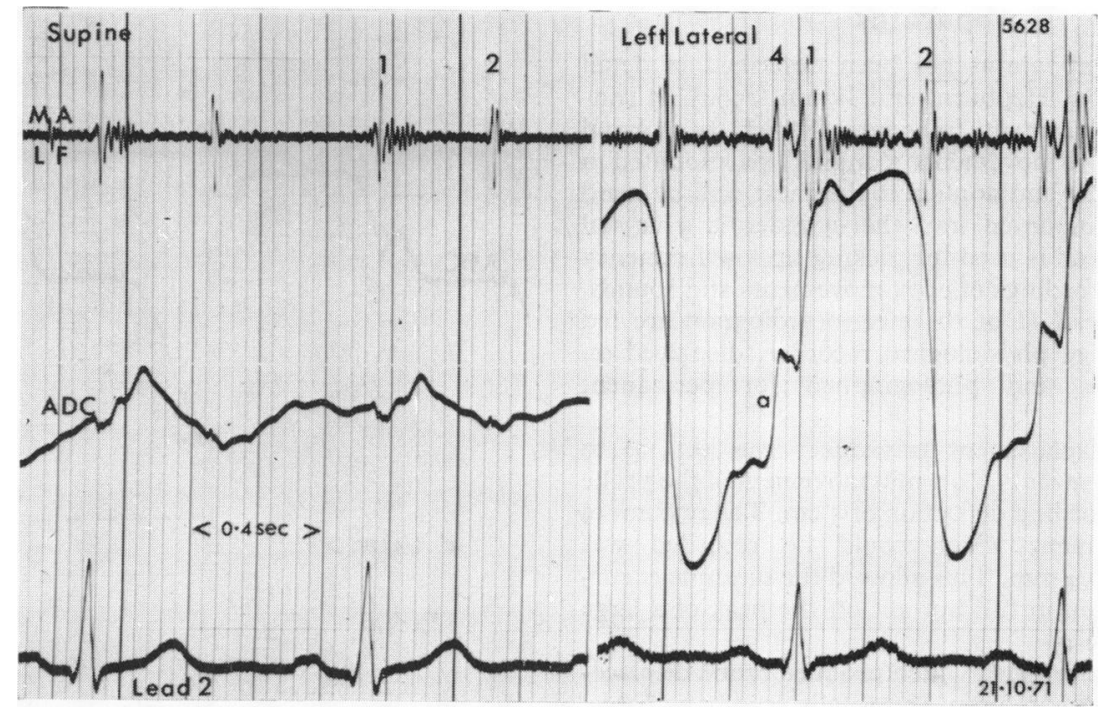

FI G. 3 Ischaemic heart disease. Lead II of the electrocardiogram, apex cardiogram ( $A D C)$, and mitral area low frequency phonocardiogram in the supine and left lateral position. The apex beat is scarcely recordable in the supine position, and the fourth sound, which is clear in the left lateral position, is lost.

palpable category. In only one patient was the apex displacement greater in the supine than the left lateral position. Fig. 3 illustrates a large apex beat in the left lateral position which is almost unrecordable in the supine position.

\section{2) Total 'a' wave height}

In the supine position, the ' $a$ ' wave was classified as moderate in 3, small in 19, and absent in 36 . In the left lateral position the ' $a$ ' wave became large in 4, moderate in 35, small in 17 , and absent in only 2. Thus the ' $a$ ' wave was recordable in 38 per cent of patients in the supine position but in 97 per cent in the left lateral position. When the ' $a$ ' wave was recordable in both positions, its mean amplitude in the supine position was $0.05 \mathrm{~mm}$ and in the left lateral position 0.1 I mm. Fig. 4 illustrates the change from a small to a moderate ' $a$ ' wave on turning the patient on his left side.

\section{3) $S_{3} /$ Sr ratio}

A third sound was recordable in 8 patients in the supine position and in 17 in the left lateral position. In the supine position the $S_{3} / S_{I}$ ratio was between $5 I$ and 100 per cent in $I$, and 50 per cent or less in the remaining 7. In the left lateral position the $S_{3} / S_{I}$ ratio was over roo per cent in 4 , between 51 and roo per cent in 2, and 50 per cent or less in II. In all 8 patients with a third sound recordable in both positions, the $\mathrm{S}_{3} / \mathrm{S}_{\mathrm{I}}$ ratio was greater in the left lateral position (mean $80 \%$ ) than in the supine position (mean $32 \%$ ).

\section{4) $S_{4} / S_{1}$ ratio}

A fourth sound was recordable in 21 cases in the supine position and 49 cases in the left lateral position. In the supine position the $\mathrm{S}_{4} / \mathrm{SI}_{\mathrm{r}}$ ratio exceeded 100 per cent in $\mathrm{I}$, was between $5 \mathrm{I}$ and 100 per cent in I, and was 50 per cent or less in 19. In the left lateral position, the $S_{4} / S_{I}$ ratio exceeded 100 per cent in 4, was between 51 and 100 per cent in 17 , and was 50 per cent or less in 28 . In only 2 cases did the $S_{4} / S_{I}$ ratio in the supine position exceed that in the left lateral position. When the fourth sound was present in both positions, the mean $\mathrm{S}_{4} / \mathrm{S}_{1}$ ratio was 30 per cent supine and 61 per cent left lateral.

\section{5) Ratio between ' $a$ ' wave height and total diastolic excursion (' $\mathbf{a}$ '/O-A)}

In 22 cases there was a measurable ' $a$ ' wave on the apex cardiogram in the supine position. In these patients the ' $\mathrm{a}$ '/O-A ratios in the supine position (mean $58 \%$ ) were very similar to those in the left lateral position (mean $60 \%$ ). In 15 of the 22 patients the ratios in each position differed by less than 15 per cent. 


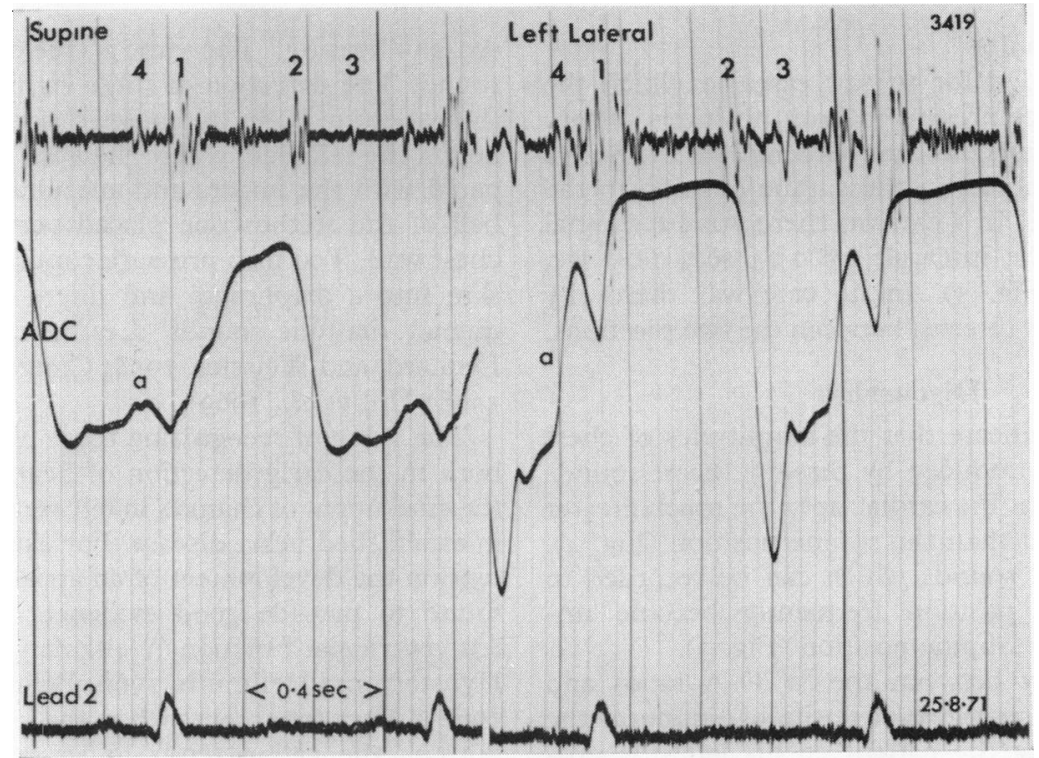

FIG. 4 Ischaemic heart disease. Abbreviations as in Fig. 2 and 3. The amplitude of the diastolic movements and sounds is much greater in the left lateral position.

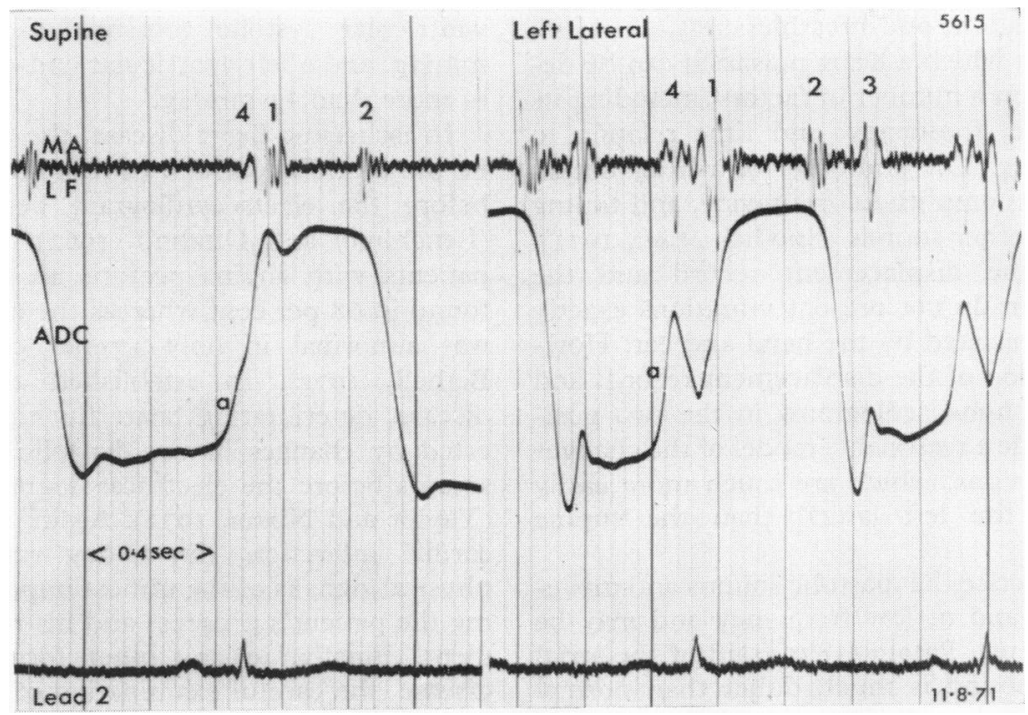

FIG. 5 Ischaemic heart disease. The $S_{4}-S_{I}$ interval is occasionally considerably longer in the left lateral than in the supine position. 


\section{6) S4-Sr interval}

This was recorded for the $2 \mathrm{I}$ cases in which the fourth sound was present in both positions. There was a slight but insignificant tendency for the $\mathrm{S}_{4}-\mathrm{S}_{\mathrm{I}}$ interval to be shorter in the supine position in the group as a whole. In 3 patients there was substantial shortening of the interval, by $0.03 \mathrm{sec}, 0.05 \mathrm{sec}$, and $0.06 \mathrm{sec}$ (Fig. 5). In no case was there any change in the PR interval between the two positions.

\section{Discussion}

These results indicate that the amplitudes of chest wall vibrations produced by diastolic heart sounds and movements at the cardiac apex are much greater in the left lateral than the supine position (Fig. 4). Movements and sounds which can be recorded in the left lateral position frequently become unrecordable in the supine position (Fig. 3 ).

The similarity between the ' $a$ ' $/ O-A$ ratios and $\mathrm{S}_{4}-\mathrm{SI}_{\mathrm{I}}$ intervals in the two positions supports the view that turning the patient on his left side produces larger chest wall vibrations without producing an important alteration in the pattern of left ventricular filling in most cases. In a few cases, however, in 3 out of 21 in this series, the $\mathrm{S}_{4}-\mathrm{S}_{1}$ interval was appreciably longer in the left lateral than in the supine position (Fig. 5) and the $\mathrm{P}-\mathrm{S}_{4}$ interval shorter. This change usually signifies deteriorating heart function (Duchosal, 1932; Kincaid-Smith and Barlow, 1959; O'Rourke, 1970) and is probably caused by increased cardiac filling in the left lateral position. It may be one reason why some patients with severe heart disease cannot lie on the left side without precipitating palpitations and breathlessness.

The ease with which a heart pulsation can be detected depends on a number of factors, including its amplitude, force, frequency, and time relation to other movements. The audibility of a heart sound depends upon its amplitude, frequency, and timing with respect to other sounds (Spodick et al., 1971). Consequently the displacement record and the phonocardiogram do not present vibrations exactly as they are appreciated by the hand and ear. However, a comparison of the displacement records and low frequency phonocardiograms in the two positions does provide a reasonable model of the changes in the physical signs, which are much more easily appreciated in the left lateral than the supine position.

In clinical practice the diastolic sounds and movements are faint and of low frequency and may be difficult to perceive. Potain (1875) said of the atrial gallop - 'This sound is much duller than normal sounds; it is a shock, a distinct pulsation, scarcely a sound. When the ear is applied to the chest, it affects the sense of touch more perhaps than the sense of hearing.' The same is true of the third heart sound. The detection of these signs, then, requires the patient to be in the most advantageous position, i.e. on the left side, where the apex beat can be palpated with the fingers and auscultated through the bell of the stethoscope placed very lightly on the chest wall. Too firm pressure converts the overlying skin into a diaphragm and filters off the low frequency diastolic sounds (Leatham, 1958; Warren, Leonard, and Weissler, 1958; Craige, 1967; Harvey, 1968; Hill et al., 1969).

The value of recognizing these physical signs lies both in the early detection of heart disease and in the assessment of changes in left ventricular function in established heart disease. For example, in hypertension the development of an atrial gallop has been found to provide good evidence of compromised left ventricular function (Weitzman, 1955; Puchner, Hyuston, and Hellmuth, 1960; Beilin and Mounsey, 1962). After treatment, when the blood pressure is normal, the gallop tends to lessen and disappear (Kincaid-Smith and Barlow, 1959; Kontos, Shapiro, and Kemp, 1963) but in some cases it persists as a clinical indicator of disease (Grayzel, 1960). In aortic stenosis there is a good correlation between the presence of an atrial gallop and the severity of the underlying haemodynamic lesion (Goldblatt, Aygen, and Braunwald, 1962; Braunwald et al., 1963; Tavel et al., 1965), particularly in adults below the age of 40 (Caulfield et al., 1971). In this situation a fourth sound with an enlarged ' $a$ ' wave is usually associated with a peak systolic gradient across the valve of $70 \mathrm{mmHg}$ or more, a peak left ventricular systolic pressure of more than 160 $\mathrm{mmHg}$, and a left ventricular end-diastolic pressure of more than II $\mathrm{mmHg}$.

In ischaemic heart disease, the atrial gallop may be the first clinical sign of heart disease, appearing before the electrocardiogram becomes abnormal (Benchimol and Dimond, 1962). In one series of patients with angina pectoris an atrial gallop was found in 68 per cent whereas the electrocardiogram was abnormal in only 17 per cent (Nixon and Bethell, 1972). In established chronic coronary disease, deteriorating heart function may be indicated by changes in the diastolic movements and sounds before the electrocardiogram has worsened (Taylor and Nixon, 1972). Again, after acute myocardial infarction, day-to-day variation in these physical signs is of the utmost importance in assessing the patient's progress and his response to treatment. Finally, in any other form of myocardial disease, the careful examination of diastolic sounds and movements of the heart permits an approximate estimation of left atrial pressure (Shah and $\mathrm{Yu}$, 1969; Cohn et al., 197r). 
In view of the valuable information about left ventricular function which can be obtained by examining the patient on his left side, and which is usually not available in the supine position, we would recommend that the examination of the heart in the left lateral position be a routine part of all clinical examinations of the cardiovascular system.

We thank Miss Anne Smith and Miss Irene Wood of the E.C.G. Department at Charing Cross Hospital for their technical help.

\section{References}

Beilin, L., and Mounsey, P. (1962). The left ventricular impulse in hypertensive heart disease. British Heart fournal, $24,409$.

Benchimol, A., and Dimond, E. G. (1962). The apex cardiogram in ischaemic heart disease. British Heart fournal, 24, $58 \mathrm{r}$.

Braunwald, E., Goldblatt, A., Aygen, M. M., Rockoff, S. D., and Morrow, A. G. (1963). Congenital aortic stenosis; clinical and hemodynamic findings in 100 patients. Circulation, 27, 426.

Caulfield, W. H., de Leon, A. C., Perloff, J. K., and Steelman, R. B. (197I). The clinical significance of the fourth heart sound in aortic stenosis. American fournal of Cardiology, 28, 179.

Cohn, P. F., Vokonas, P. S., Williams, R. A., Herman, M. V., and Gorlin, R. (197I). Diastolic heart sounds and filling waves in coronary artery disease. Circulation, 44, 196.

Craige, E. (1967). Gallop rhythm. Progress in Cardiovascular Diseases, 10, 246.

Duchosal, P. (1932). A study of gallop rhythm by a combination of phonocardiographic and electrocardiographic methods. American Heart fournal, 7, 613.

Goldblatt, A., Aygen, M. M., and Braunwald, E. (1962). Hemodynamic - phonocardiographic correlations of the fourth heart sound in aortic stenosis. Circulation, 26, 92.

Grayzel, J. (1960). Gallop rhythm of the heart. I. Atrial gallop, ventricular gallop and systolic sounds. American fournal of Medicine, $28,578$.

Harvey, W. P. (1968). Some newer or poorly recognised findings on clinical auscultation (II). Modern Concepts of Cardiovascular Disease, 37, 89.

Hill, J. C., O'Rourke, R. A., Lewis, R. P., and McGranahan, G. M. (1969). The diagnostic value of the atrial gallop in acute myocardial infarction. American Heart fournal, 78, 194.

Kincaid-Smith, P., and Barlow, J. (1959). The atrial sound in hypertension and ischaemic heart disease. British Heart fournal, 21, 479.

Kontos, H. A., Shapiro, W., and Kemp, V. E. (1963). Observations on the atrial sound in hypertension. Circulation, 28,877 .

Leatham, A. (1952). Phonocardiography. British Medical Bulletin, 8, 333.

Leatham, A. (1958). Auscultation of the heart. Lancet, 2, 703.

Nixon, P. G. F., and Bethell, H. J. N. (1972). Atrial gallop in diagnosis of early coronary heart disease (abstract). British Heart fournal, 34, 202.

Nixon, P. G. F., Hepburn, F., and Ikram, H. (1964). Simultaneous recording of heart pulses and sounds. British Medical fournal, I, I 169.

O'Rourke, R. A. (1970). The atrial sound. Factors regulating its occurrence and timing. American Heart fournal, 80, 715.

Potain, P. C. (1875). Du rhythme cardiaque appelée bruit de galop, de son mécanisme et de sa valeur séméiologique. Bulletins et Mémoires de la Société Médicale des Hôpitaux de Paris, I2 (deuxième série) Memoires, Année 1875, pp. 137-166. (Quoted by McKusick, V. A. (1958). In Cardiova cular Sound in Health and Disease. Williams and Wilkins, Baltimore.)

Puchner, T. C., Hyuston, J. H., and Hellmuth, G. A. (I960). Heart sounds and murmurs in arterial hypertension. American fournal of Cardiology, 6, 630 .

Shah, P. M., and Yu, P. N. (I969). Gallop rhythm. Hemodynamic and clinical correlation. American Heart fournal, $78,823$.

Spodick, D. H., Rectra, E., Khan, A., and Pigott, V. (1971). Audibility of the fourth heart sound: a prospective, blinded investigation (abstract). Circulation, 44, Suppl. II, 33.

Tavel, M. E., Campbell, R. W., Feigenbaum, H., and Steinmetz, E. F. (1965). The apex cardiogram and its relationship to haemodynamic events within the left heart. British Heart fournal, 27, 829.

Taylor, D. J. E., and Nixon, P. G. F. (1972). Assessment of left ventricular function after myocardial infarction. British Heart fournal, 34, 905.

Warren, J. V., Leonard, J. J., and Weissler, A. M. (1958). Gallop rhythm. Annals of Internal Medicine, 48, 580.

Weitzman, D. (1955). Mechanism and significance of the auricular sound. British Heart fournal, 17, 70.

Requests for reprints to Dr. P. G. F. Nixon, Cardiac Department, Charing Cross Hospital, Fulham Palace Road, London W6 8RF. 